\title{
Correction to: The Novel Small Molecule TRVA242 Stabilizes Neuromuscular Junction Defects in Multiple Animal Models of Amyotrophic Lateral Sclerosis
}

\author{
Poulomee Bose $^{1,2} \cdot$ Elsa Tremblay $^{1,3}$. Claudia Maios ${ }^{2}$ - Vijay Narasimhan ${ }^{4}$. Gary A. B. Armstrong ${ }^{5} \cdot$ Meijiang Liao $^{1,2}$. \\ J. Alex Parker ${ }^{1,2} \cdot$ Richard Robitaille $^{1,3} \cdot$ Xiao Yan Wen $^{4} \cdot$ Christopher Barden $^{6} \cdot$ Pierre Drapeau $^{1,2}$
}

Published online: 7 June 2021

(c) The American Society for Experimental NeuroTherapeutics, Inc. 2021
Publisher's Note Springer Nature remains neutral with regard to jurisdictional claims in published maps and institutional affiliations.

This correction is to update an author's name. The correct spelling is Claudia Maios.

The original article has been corrected.

The original article can be found online at https://doi.org/10.1007/ s13311-019-00765-w.

Pierre Drapeau

p.drapeau@umontreal.ca

1 Department of Neuroscience, Université de Montréal, Montréal, Quebec, Canada

2 Centre de Recherche du Centre Hospitalier de L'Université de Montréal (CRCHUM Tour Viger R09-482), 900 Rue Saint Denis, Montréal, Quebec H2X 0A9, Canada

3 FRQS Group de Recherche Sur Le System Nerveux Centrale, Montreal, Canada

4 Zebrafish Centre for Advanced Drug Discovery and Keenan Research Centre for Biomedical Science, Li Ka Shing Knowledge Institute, St. Michael's Hospital and Department of Medicine and Physiology, University of Toronto, Toronto, Ontario, Canada

5 Department of Neurology and Neurosurgery, McGill University and Montreal Neurological Institute, Montreal, Canada

6 Treventis Corporation, 60 Leonard Avenue, Toronto, Ontario, Canada 